\title{
Versatile cyclodextrin nanotube synthesis with functional anchors for efficient ion channel formation: design, characterization and ion conductance $\uparrow$
}

\begin{abstract}
Hajar Mamad-Hemouch, ${ }^{a}$ Laurent Bacri, (DD*a Cécile Huin, ${ }^{a}$ Cédric Przybylski, (D) ${ }^{b}$ Bénédicte Thiébot, ${ }^{\mathrm{c}}$ Gilles Patriarche, (D) ${ }^{\mathrm{d}}$ Nathalie Jarroux ${ }^{\star a}$ and Juan Pelta (D) *a

Biomimetic ion channels with different materials have been extensively designed to study the dynamics in a confined medium. These channels allow the development of several applications, such as ultra-fast sequencing and biomarker detection. When considering their synthesis, the use of cheap, non-cytotoxic and readily available materials is an increasing priority. Cyclodextrins, in supramolecular architectures, are widely utilized for pharmaceutical and biotechnological applications. Recent work has shown that short nanotubes (NTs) based on alpha-cyclodextrin ( $\alpha-C D)$ assemble transient ion channels into membranes without cytotoxicity. In this study, we probe the influence of new cyclodextrin NT structural parameters and chemical modifications on channel formation, stability and electrical conductance. We report the successful synthesis of $\beta$ - and $\gamma$-cyclodextrin nanotubes ( $\beta$-CDNTs and $\gamma$-CDNTs), as evidenced by massspectrometry and high-resolution transmission electron microscopy. CDNTs were characterized by their length, diameter and number of CDs. Two hydrophobic groups, silylated or vinylated, were attached along the $\gamma$-CDNTs, improving the insertion time into the membrane. All NTs synthesized form spontaneous biomimetic ion channels. The hydrophobic NTs exhibit higher stability in membranes. Electrophysiological measurements show that ion transport is the main contribution of NT conductance and that the ion energy penalty for the entry into these NTs is similar to that of biological channels.
\end{abstract}

\section{Introduction}

Biological channels, with electrical detection, are extensively used to sense ions, polymers and biomolecules. ${ }^{1-5}$ These highly reproducible recombinant channels are selective, sensitive and stable within a lipid membrane. The net flow of water through a channel depends on ion selectivity and applied voltage sign, and influences the dynamics of the molecules. ${ }^{6-11}$ Recently, the control of the electro-osmotic flow through a protein channel has been used to capture and detect several peptides as biomarker models. ${ }^{12}$ This method has been the basis for numerous applications including ultra-fast DNA/RNA

\footnotetext{
${ }^{a} L A M B E$, Université Evry, CNRS, CEA, Université Paris-Saclay, 91025 Evry, France. E-mail:Juan.Pelta@univ-evry.fr, nathalie.jarroux@univ-evry.fr, laurent.bacri@univ-evry.fr

${ }^{b}$ Université Pierre et Marie Curie, Institut Parisien de Chimie Moléculaire, CNRS UMR 8232, 4 place Jussieu, 75252 Paris Cedex 05, France ${ }^{c} L A M B E$, Université Cergy-Pontoise, Université Paris-Seine, 91025 Evry, France ${ }^{d}$ Centre de Nanosciences et de Nanotechnologies, CNRS, Université Paris-Sud, Université Paris-Saclay, C2N-Marcoussis, Marcoussis 91460, France $\dagger$ Electronic supplementary information (ESI) available. See DOI: 10.1039/ c8nr02623h
}

sequencing, ${ }^{13,14}$ single molecule mass spectrometry, ${ }^{15-21}$ peptide and protein detection, ${ }^{7,22-28}$ protein unfolding, ${ }^{29-32}$ and real-time enzymatic assay. ${ }^{19,33-36}$

For the past two decades, numerous teams have designed and manufactured new biomimetic channels striving to obtain the same sensitivity and selectivity as biological channels. To achieve this, improved environmental resistance to applied voltages or chaotropic agents and pressure and an increase in the observation scale, from sequence determination to particle detection, are sought. ${ }^{37-40}$ Thanks to the recent advances in nanotechnology and materials science, new classes of biomimetic nanopores have emerged. Among them, drilled solidstate membranes based on silica, ${ }^{41}$ polymer $^{42}$ or graphene ${ }^{43,44}$ materials have been used for DNA sequencing, ${ }^{45-47}$ viral detection, ${ }^{48-50}$ micro-RNA identification, ${ }^{51}$ protein size or conformational change observation, ${ }^{52-58}$ and protein biomarker models. ${ }^{59,60}$ Nevertheless, these nanopores are limited by high production cost, a lack of selectivity, low responsiveness to stimuli and low reproducibility. Bio-inspired synthetic nanopores with natural bilayers or with protein scaffolding have also been used to mimic protein translocation ${ }^{61}$ and the nuclear pore complexes. ${ }^{62}$ Other synthetic channels have been 
designed from macrocycles, ${ }^{63}$ peptides ${ }^{64}$ and more recently using surface functionalized ordered hybrid porous solids ${ }^{65,66}$ to control the ionic conductance and selectivity in lipid membranes.

The fast development of DNA origami created a need for the development of tri-dimensional DNA nanopores. ${ }^{67}$ These nanopores have been used to unzip the DNA hairpin ${ }^{68}$ to study DNA translocation ${ }^{69}$ for the controlled transport of charged molecules through the molecular valve. ${ }^{70}$ The open and closed state of these channels can be controlled by applied voltages. ${ }^{71}$ Hydrophobic molecules, such as cholesterol or porphyrin, have been used as lipid anchors for lipid membrane insertion of these biomimetic ion channels ${ }^{72,73}$ and also for thermophage portal protein. ${ }^{74}$ Recently, short carbon nanotubes inserted into lipid membranes have been used to study ion transport and DNA translocation. ${ }^{75,76}$ Nevertheless, cytotoxicity remains a major concern with these DNA and carbon biomimetic channels. ${ }^{77,78}$

To overcome this hurdle, we previously decided to use natural and biocompatible molecules, such as cyclodextrins (CDs), to manufacture short nanotubes to form biomimetic ion channels. ${ }^{79}$ Modified CDs are well-known to form transition-conducting channels ${ }^{80-84}$ and have also been used as molecular adaptors to improve the sensitivity of the nanopore itself. ${ }^{85} \mathrm{CDs}$ are natural cyclic oligosaccharides obtained by enzymatic conversion of starch. Their cavity sizes depend on the number of glucopyranose units, i.e. 6, 7 or 8 corresponding to $\alpha-, \beta$ - or $\gamma$-CDs, respectively. They are soluble in aqueous solution and can easily encapsulate molecules inside their hydrophobic cavity. ${ }^{86}$ Cyclodextrins are versatile platforms which can be functionalized ${ }^{87}$ or used in supramolecular assemblies. ${ }^{88}$ Their interesting properties are extensively used in pharmaceutical, food, cosmetic and textile industries such as in drug formulation, nucleic acid delivery or in bioconversion processes..$^{89,90}$ Recently, we successfully manufactured and characterized short biomimetic NTs based on $\alpha$-CD with a sub-nanometric diameter. ${ }^{79}$ We showed that these NTs form spontaneous transient ion channels in lipid membranes, the conductance of which was mainly due to the transport of ions. Interestingly, under our previous experimental conditions, these NTs did not alter the mitochondrial dehydrogenase activity or the morphology of living cells.

The next challenge is to establish a general synthesis pathway to obtain versatile nanotubes with controllable structural parameters and ionic conductance that are more stably inserted into lipid membranes.

Here, we successfully designed a user-friendly and reliable route to build new $\beta$ - and $\gamma$-CD based nanotubes ( $\beta$-CDNTs and $\gamma$-CDNTs) and functionalized $\gamma$-CDNTs with hydrophobic group anchors. Until now, few studies have reported polyrotaxane synthesis based on low threading rate $\beta$ - and $\gamma$-CD molecules along the polymer. ${ }^{91-95}$ The main challenge is to limit the CD unthreading during their synthesis. ${ }^{96}$ To the best of our knowledge, the design and the synthesis of $\beta$-CDNTs and $\gamma$-CDNTs have not been reported yet. Thanks to a radical coupling reaction optimization previously described ${ }^{97}$ and suitable operating conditions, CD-based polyrotaxanes can be synthesized faster and used as precursors for NT construction. These supramolecular assemblies lead to biomimetic ion channels, which are systematically characterized by mass-spectrometry, high-resolution transmission electron microscopy and electrophysiological measurements.

\section{Results and discussion}

\section{Design, synthesis and characterization of $\beta$ - and $\gamma$-cyclodextrin nanotubes}

The general route to produce CDNTs from polyrotaxanes based on $\beta$ - and $\gamma$-CDs consists of four reaction steps: (1) formation of an inclusion complex called pseudopolyrotaxane which consists in CDs threaded on a polymer chain; (2) addition of bulky pyrene groups at each end-chain leading to a polyrotaxane; (3) formation of the NTs by covalently bridging each CD and; (4) hydrolysis of the blocking groups leading to the NTs. Taking CD's cavity sizes and the kind of polymer into account, our synthesis route (Fig. 1) permits us to manufacture singlestranded polyrotaxanes. Polyrotaxanes are made from poly (propylene oxide) (PPO) and $\beta$-CD and also from poly(isobutylene) (PIB) and $\gamma$-CD leading, respectively, to $\beta$-CDNT and $\gamma$-CDNT formation. This route also permits us to synthesize double stranded polyrotaxanes such as two poly(ethylene oxide) (PEO) and $\gamma$-CDs leading also to $\gamma$-CDNT formation.

Cyclodextrin nanotubes with various constitutive elements were synthesized i.e. $\beta$-CD and PPO with a molecular mass of $2000 \mathrm{~g} \mathrm{~mol}^{-1}$ ( $\beta$-CDNT2000), $\gamma$-CD and PIB with a molecular mass of 2300 and $20000 \mathrm{~g}$ mol$^{-1}(\gamma$-CDNT2300 and $\gamma$-CDNT20000, respectively) and $\gamma$-CD with two chains of PEO for a molecular mass of $1000 \mathrm{~g} \mathrm{~mol}^{-1}(\gamma-\mathrm{CDNT} 1000 ")$. The synthesis of $\alpha$-CDNTs has been previously described ${ }^{79}$ the preparation scheme is recalled in ESI Scheme S1. $\dagger$

MALDI-TOF MS analysis is performed both in linear and reflector modes to probe the various mass distributions and to attribute each peak in relation to the diversity of the structural content. These spectra successfully show the expected general structure of polyrotaxane. Each distribution of the spectrum presents a population of polyrotaxane composed of a given number of CDs. Similarly, each peak within a given distribution reflects both the polydispersity of the polymer and variable numbers of bridges between the CDs. Such results are of prime importance to ensure that the threading rate of CDs on the polyrotaxane molecules is enough to allow an efficient NT synthesis. For CDNTs reported herein, MALDI TOF MS spectra acquired in linear mode offer a good snapshot of the sample content as reported in Fig. 2-4. Such spectra show that each center of mass distribution is 1295.5 Da (Fig. 2 and 4) and 1134.3 Da (Fig. 3) matching with the molecular weight of $\gamma$-CD and $\beta-\mathrm{CD}$, respectively. The analysis in reflector mode gives an opportunity to obtain fine structural data for a given distribution, especially on the modifications occurring on the primary and secondary rims of CDs (detailed description in the ESI†). The analysis of high mass nanotubes by this tech- 


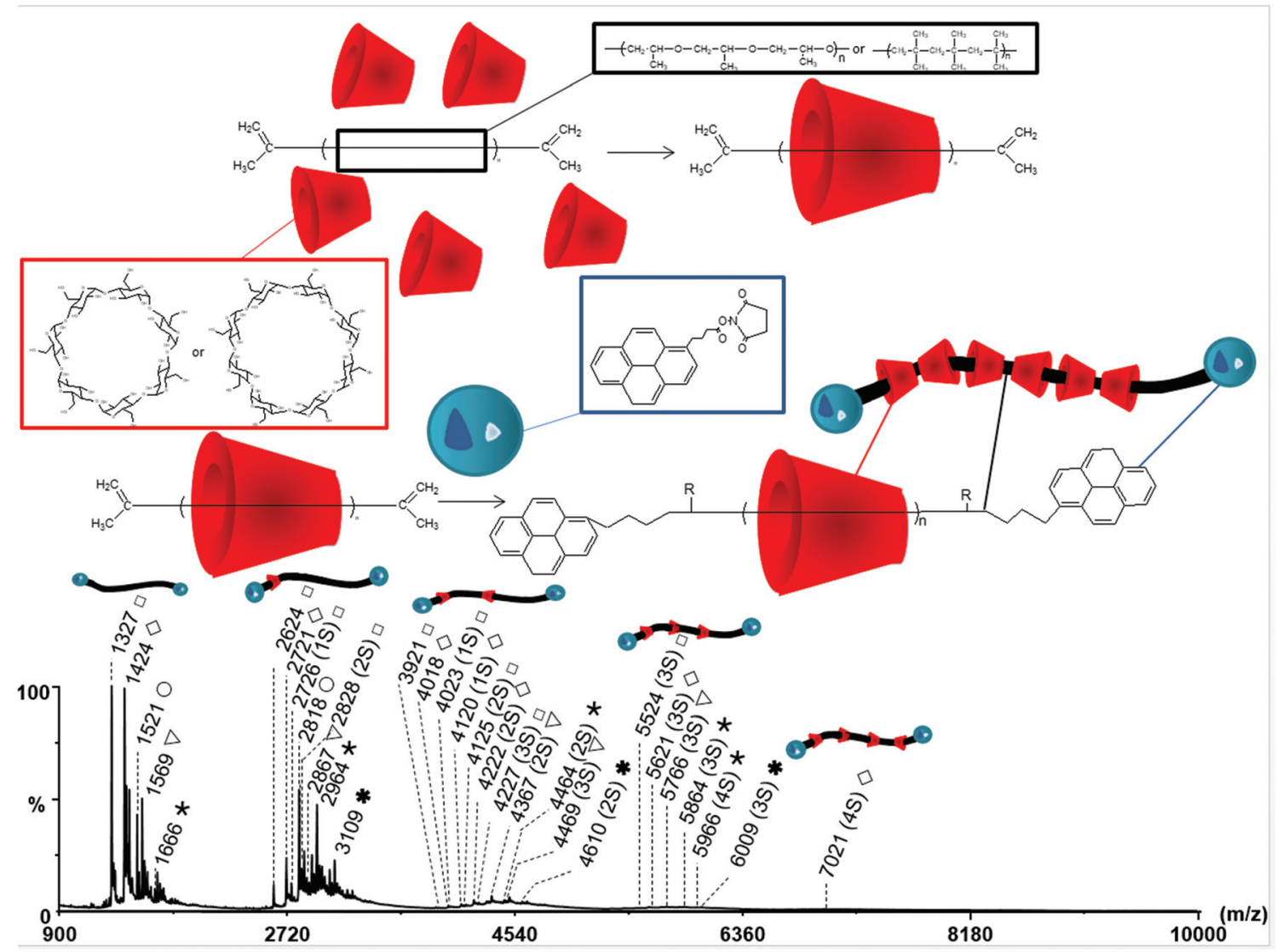

Fig. 1 Summary of the polyrotaxane synthesis route as precursors of $\beta$-CDNT2000 and $\gamma$-CDNT1000"/20000 and characterization results obtained by MALDI-TOF MS. $\beta$ - or $\gamma$-CDs are represented in red, the $\alpha-\omega$ diallyl polymer is colored in black and the pyrene-based blocking groups are colored in blue. (a) Pseudopolyrotaxane synthesis, (b) polyrotaxane synthesis and (c) positive MALDI-TOF mass spectrum of PR involving CD and PIB 2300 obtained in linear mode. PR was mixed with THAP/TMG 2 in DMF. ${ }^{98}$ Even if lithium and potassium adducts were also observed, some examples of putative assignment were given considering only prominent sodiated ions for clarity and the sulfate content in $\mathrm{CDs}(\mathrm{xS})$ as follows: $\mathrm{Py}(\mathrm{H})-$ $\left(\mathrm{CH}_{2}\left(\mathrm{CH}_{3}\right)_{2}\right)_{10}-(\mathrm{H}) \mathrm{Py}(\square), \mathrm{Py}(\mathrm{H})-\left(\mathrm{CH}_{2}\left(\mathrm{CH}_{3}\right)_{2}\right)_{10}-(\mathrm{S}) \mathrm{Py}(\diamond), \mathrm{Py}(\mathrm{S})-\left(\mathrm{CH}_{2}\left(\mathrm{CH}_{3}\right)_{2}\right)_{10}-(\mathrm{S}) \mathrm{Py}(\mathrm{O}), \mathrm{Py}(\mathrm{Py})-\left(\mathrm{CH}_{2}\left(\mathrm{CH}_{3}\right)_{2}\right)_{10}-(\mathrm{H}) \mathrm{Py}(\nabla), \mathrm{Py}(\mathrm{Py})-\left(\mathrm{CH}_{2}\left(\mathrm{CH}_{3}\right)_{2}\right)_{10}-(\mathrm{S}) \mathrm{Py}$ $(\star)$ and $\mathrm{Py}(\mathrm{Py})-\left(\mathrm{CH}_{2}\left(\mathrm{CH}_{3}\right)_{2}\right)_{10}-(\mathrm{Py}) \mathrm{Py}\left({ }^{*}\right)$. Further details are given in ESI Table S1. $\dagger$

nique remains very difficult to perform. To obtain the best resolution, we have tested several matrices. Moreover, we have observed, under our experimental conditions, up to six cyclodextrin units by using nanotubes.

The manufactured NTs from the polyrotaxane populations are also analyzed by High-Resolution Transmission Electron Microscopy (HRTEM) to overcome mass limitation. Indeed, quantitative structural parameters were obtained by HRTEM experiments with $\gamma$-CDNT2300, $\gamma$-CDNT20000, $\beta$-CDNT2000 and $\gamma$-CDNT1000". The statistical analysis of the structural parameters extracted from the HRTEM pictures leads to distributions of NTs as a function of their lengths and diameters (Fig. 2-4). Thus, data obtained reveal average lengths of $2.4 \pm$ $0.7 \mathrm{~nm}$ with $4 \pm 2 \gamma$-CDs, $4.4 \pm 0.9 \mathrm{~nm}$ with $8 \pm 2 \gamma$-CDs and $3.2 \pm 1.1 \mathrm{~nm}$ with $5 \pm 2 \gamma$-CDs for $\gamma$-CDNT2300, $\gamma$-CDNT20000, and $\gamma$-CDNT1000", respectively. $\beta$-CD based NTs i.e. $\beta$-CDNT2000 present a length of $2 \pm 0.4 \mathrm{~nm}$ with $3 \pm 1 \beta$-CD. The average values gathered from Gaussian fits of each distribution are shown in Table 1 . Using $\gamma$-CDNT2300 and $\gamma$-CDNT20000, we observe that $\gamma$-CDNT20000 is twice as long as $\gamma$-CDNT2300 while we would have expected it to be longer. This surprising result could be explained by the behavior in solution of the PIB versus the CDs, leading to the unthreading of CDs during the polyrotaxane synthesis step (Fig. 1a). We can interpret that during the nanotube synthesis i.e. crosslinking between CDs, a part of the CD assembly might have been separated from PIB moieties, evidenced by the turbid solution in water (bad solvent conditions). We hypothesize that CDs would get closer to each other, and therefore they would crosslink, thereby reducing the nanotube length.

Now, we compare the diameters of $\gamma$-CDNT2300 and $\gamma$-CDNT1000" (Table 1). They have a diameter of $4.2 \pm 0.4 \AA$ and $3.6 \pm 0.5 \AA$, respectively. This slight difference of the diameter is linked to the synthetic pathway. Even considering that these results are close enough, the values might show that $\gamma$-CDNT1000" undergoes a possible diameter restriction and an elongation of the CD length. It could be due to the twist effect generated by the flexibility of $\gamma \mathrm{CDs}$ and the use of two PEO chains instead of a single PIB chain for $\gamma$-CDNT2300. To improve the insertion time of the nanotubes inside lipid mem- 

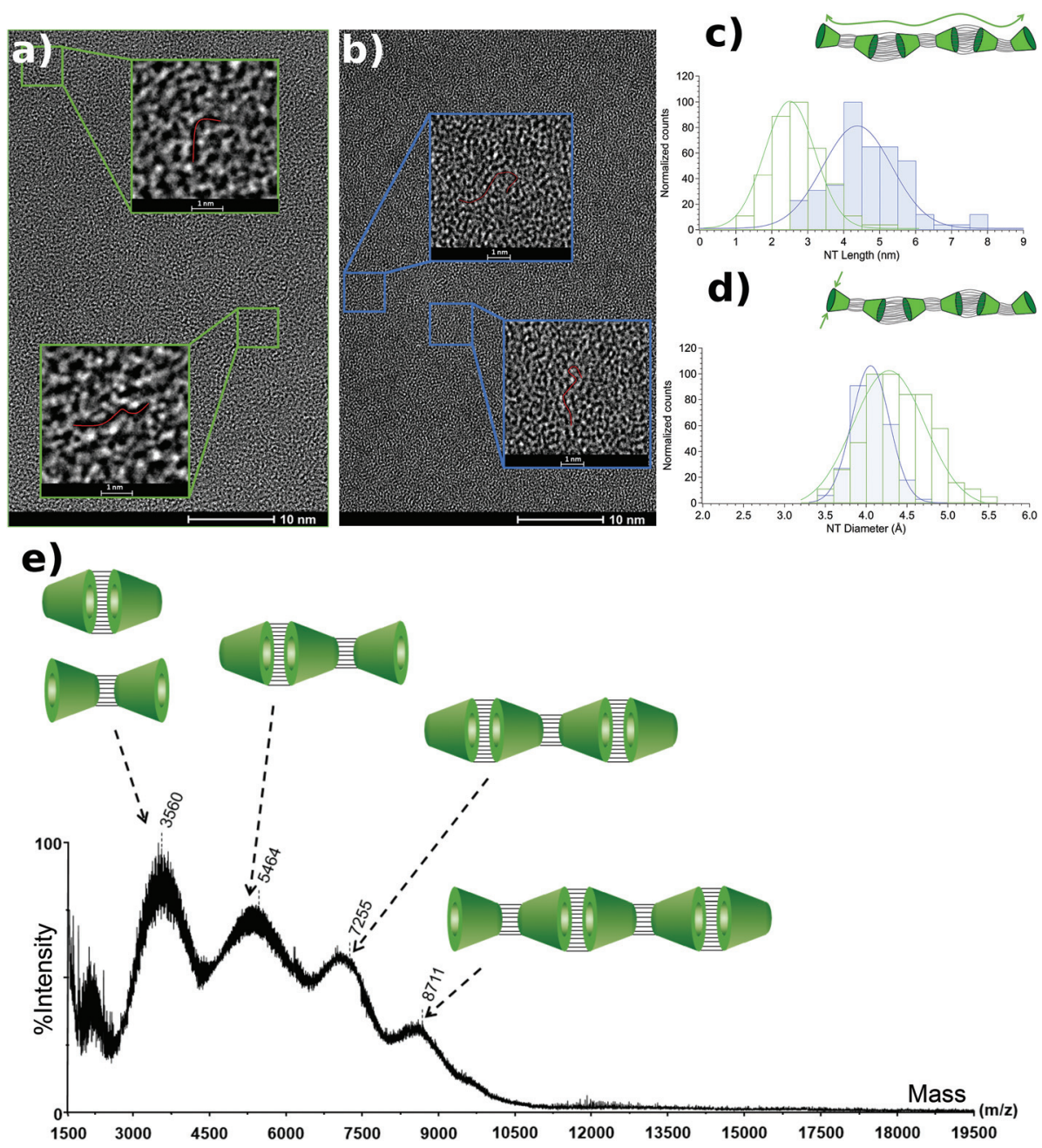

Fig. 2 HRTEM and MALDI-TOF MS analysis of $\gamma$-CDNT2300. (a) Picture of $\gamma$-CDNT2300 obtained with conventional HRTEM and magnified on the areas delineated by the green frames. (b) Picture of $\gamma$-CDNT20000 obtained with conventional HRTEM and zooms on the areas delineated by the blue frames. (c) Length distribution of $\gamma$-CDNT2300 $\left(l_{N T}=2.4 \pm 0.7 \mathrm{~nm}\right)$ and $\gamma$-CDNT20000 $\left(l_{N T}=4.4 \pm 0.9 \mathrm{~nm}\right)$ measured from HRTEM images. (d) Diameter distribution of $\gamma$-CDNT2300 $(\varnothing=4.2 \pm 0.4 \AA)$ and $\gamma$-CDNT20000 ( $\varnothing=4.0 \pm 0.3 \AA$ ) measured from HRTEM images. (e) MALDI-TOF spectrum in linear mode and negative polarity. Further details are given in ESI Table S2. $\dagger$

branes, we performed two types of $\gamma$-CDNT2300 chemical modifications. The first modification is a silylation of the hydroxyl groups of the nanotube with trimethylsilyl moieties leading to a silylated nanotube called $\gamma$-CDNT2300Si. A second batch of $\gamma$-CDNT2300 was modified by vinyl ether moieties, thanks to nucleophilic substitution between the hydroxyl groups of $\gamma \mathrm{CDNT2300}$ and 2-chloroethyl vinyl ether, leading to a vinylated nanotube called $\gamma$-CDNT2300Vi.

\section{Ion channel formation in lipid membranes, stability and ionic conductance}

As the lipid membrane behaves as an insulator, we do not observe any ionic flow through the membrane in the absence of insertion. In this case, the average ionic current is null. New $\beta$ - and $\gamma$-CD based NTs' structural parameters and chemical modifications were probed for biomimetic channel insertion and stability into a lipid bilayer (Fig. 5a). The ion transport was tested using these NTs in a confined medium. Lipid membrane stability was checked for a few hours; no spikes were observed when a steady voltage was applied. After the addition of the $\gamma$-CDNT, several current drops appeared (Fig. 5b). The histogram depicted in Fig. $5 \mathrm{c}$ shows four distinct peaks within this trace, and each of them is fitted by a Gaussian law, which reads $A \exp \left(-\left(I-I_{\mathrm{p}}\right)^{2} /\left(2 \sigma^{2}\right)\right)$, where $A$ is the peak amplitude, $I_{\mathrm{p}}$ is the peak position and $\sigma$ is the variance (Fig. 5c). Each peak is numbered and corresponds to the insertion of one single NT, as shown by the linear fit of the current steps as a function of the number of inserted channels (Fig. 5d). The slope $80 \pm$ 9 pS defines the unitary conductance of the CDNT for an applied voltage of $80 \mathrm{mV}$. To plot the current-voltage characteristics of this channel, we repeated this procedure by increasing the applied voltage from $-100 \mathrm{mV}$ to $+100 \mathrm{mV}$. This biomimetic channel follows typical Ohm's behavior with the current responding in a linear trend as a function of the 

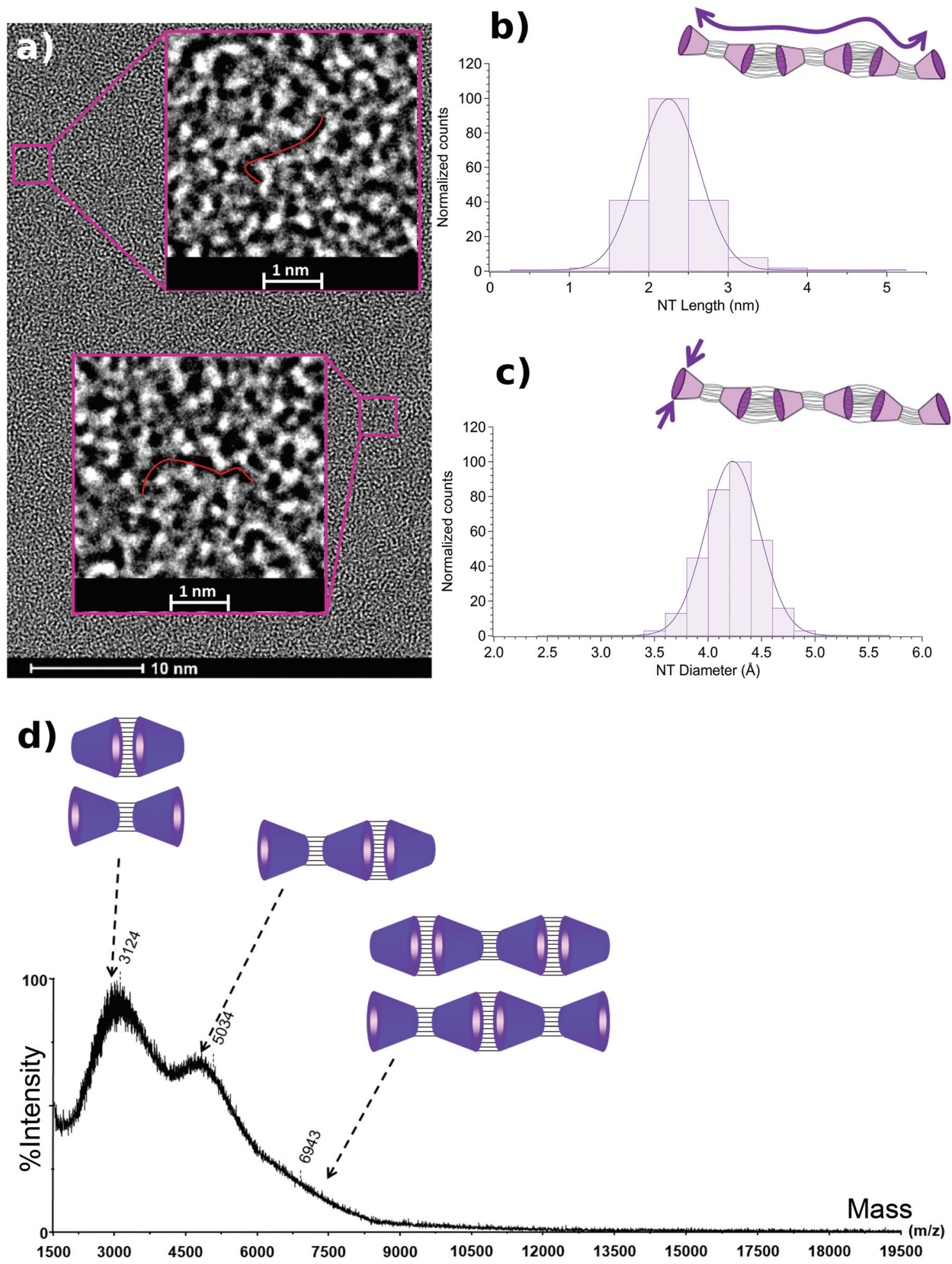

Fig. 3 HRTEM and MALDI-TOF MS analysis of $\beta$-CDNT2000. (a) Picture of $\beta$-CDNT2000 obtained with conventional HRTEM and zooms on the areas delineated by the purple frames. (b) Length distribution of $\beta$-CDNT2000 measured from HRTEM images $\left(l_{\mathrm{NT}}=2.0 \pm 0.4 \mathrm{~nm}\right.$ ). (c) Diameter distribution of $\beta$-CDNT2000 measured from HRTEM images $(\varnothing=4.1 \pm 0.3 \AA$ A). (d) Spectrum in linear mode and negative polarity. Further details are given in ESI Table S3. $\dagger$

applied voltage under our experimental conditions. The $\gamma$-CDNT conductance found is $76 \pm 2 \mathrm{pS}$. This measurement is consistent with the unitary current measured at $80 \mathrm{mV}$. We have previously observed the same conductance of $77 \pm 5 \mathrm{pS}$ with $\alpha$-CDNTs. ${ }^{79}$ This behavior allows us to believe that the conductance is due to the ionic transport through the NT. 

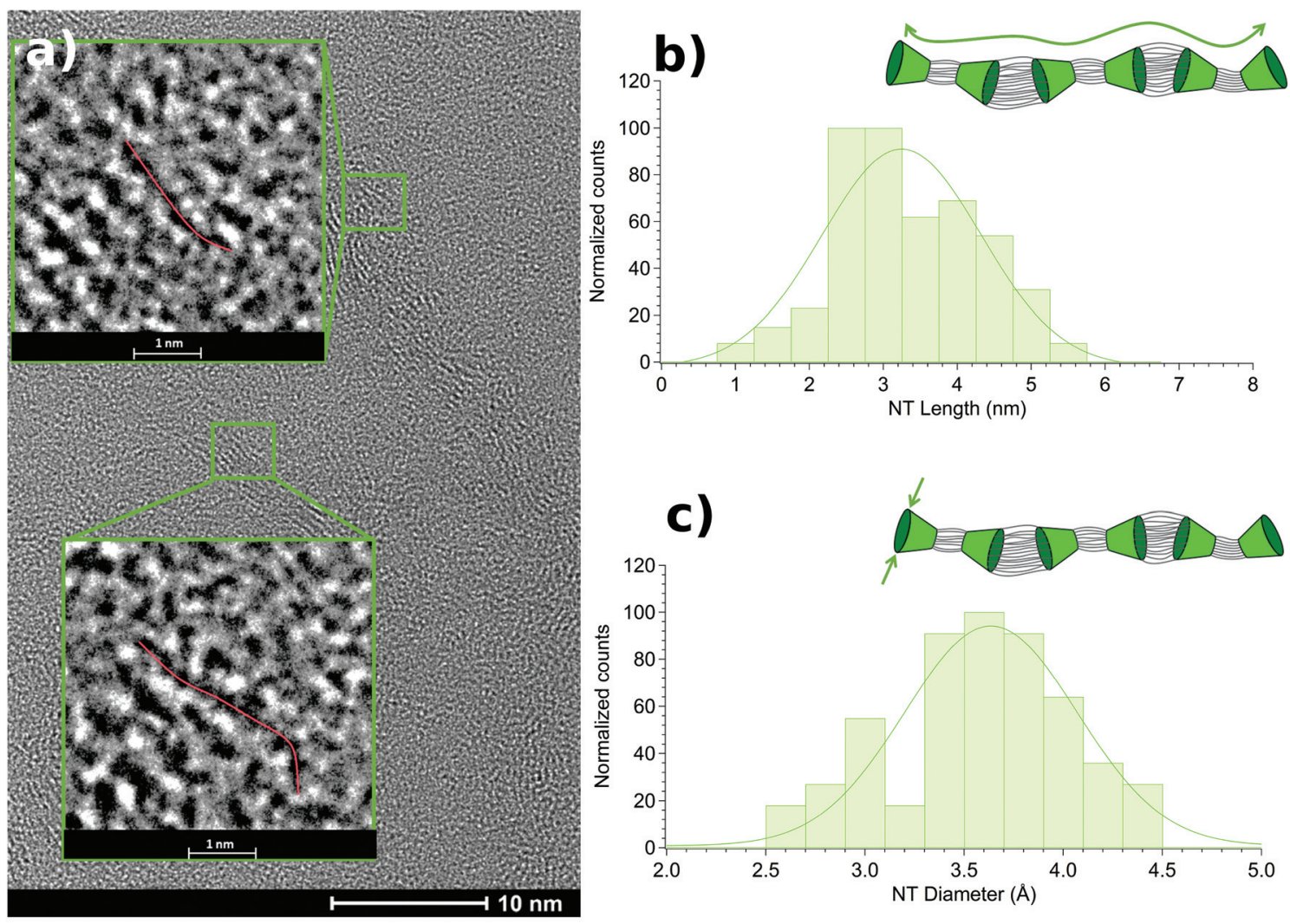

\section{d)}
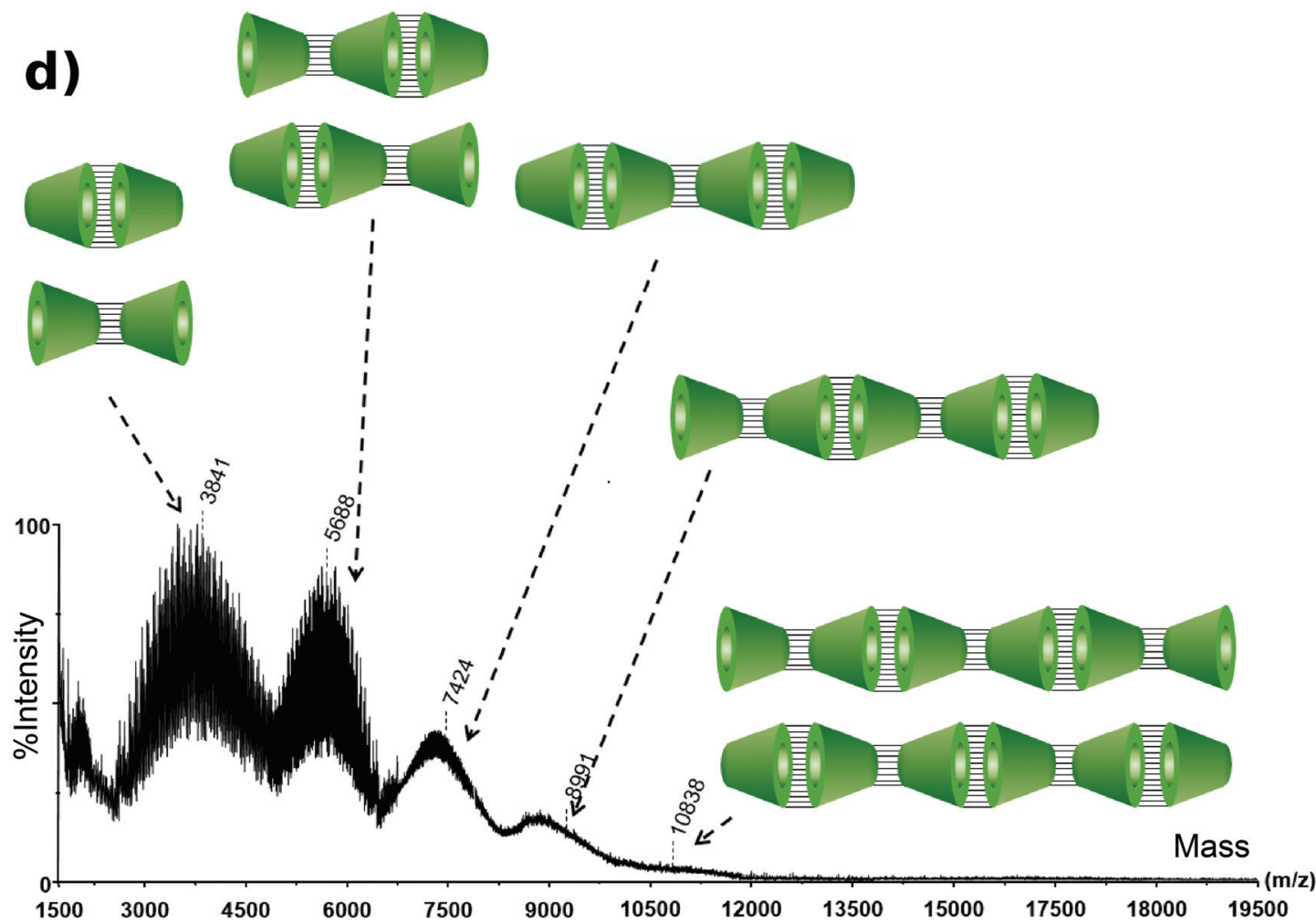

Fig. 4 HRTEM and MALDI-TOF MS analysis of $\gamma$-CDNT1000". (a) Picture of $\gamma$-CDNT1000" obtained with conventional HRTEM and zooms on the areas delineated by the green frames. (b) Length distribution of $\gamma$-CDNT1000" measured from HRTEM images $\left(l_{N T}=3.2 \pm 1.1 \mathrm{~nm}\right)$. (c) Diameter distribution of $\gamma$-CDNT1000" measured from HRTEM images $(\varnothing=3.6 \pm 0.5 \AA$ ). (d) Spectrum in linear mode and negative polarity. Further details are given in ESI Table S4.† 
Table 1 Average structural parameters of $\beta$-CDNT2000, $\gamma$-CDNT2300, $\gamma$-CDNT1000" and $\gamma$-CDNT20000 obtained after statistical measurements of HRTEM images, where $L_{N T}$ is the length of the nanotube, $\varnothing_{N T}$ is its diameter, $n_{\mathrm{CD}}$ is its number of cyclodextrins, and $L_{C D}$ is the length of each cyclodextrin composing the nanotube

\begin{tabular}{lllll}
\hline & $L_{\mathrm{NT}}(\mathrm{nm})$ & $\varnothing_{\mathrm{NT}}(\AA)$ & $L_{\mathrm{CD}}(\AA)$ & $n_{\mathrm{CD}}$ \\
\hline$\beta$ CDNT2000 & $2.4 \pm 0.7$ & $4.1 \pm 0.3$ & $5.6 \pm 0.5$ & $3 \pm 1$ \\
$\gamma$ CDNT2300 & $2.4 \pm 0.7$ & $4.2 \pm 0.4$ & $5.4 \pm 0.6$ & $4 \pm 2$ \\
$\gamma$ CDNT1000" & $3.2 \pm 1.1$ & $3.6 \pm 0.5$ & $6.4 \pm 0.4$ & $5 \pm 2$ \\
$\gamma$ CDNT20000 & $4.4 \pm 0.9$ & $4.0 \pm 0.3$ & $5.1 \pm 0.5$ & $8 \pm 2$
\end{tabular}

Potential applications in the biological or biotechnological fields using subnanometric NTs depend on their lifetime control of the sensor stability in the lipid bilayer and on their capability to avoid or limit multiple channel insertions into the membrane. To reach this goal, raw CDNTs can be chemically modified to enhance their insertion stability while avoiding aggregation.

We have previously demonstrated that silylated groups attached to $\alpha$-CDNTs do not modify the structural parameters of the channel and prevent supramolecular organization of the NT. ${ }^{79}$ The effect of silylation modification on nanotube channel formation and stability has never been studied. With designed silylated $\gamma$-CDNTs, we can observe that the time of insertion of this modified NT is longer than the recording time (at least 15 seconds, Fig. 6a). The best interpretation is that the substitution of the hydroxyl groups by silylated groups increases the nanotube hydrophobicity and favors its insertion in the lipidic bilayer, while preventing self-aggregation. The NT's unitary current from the current histogram (Fig. 6b) is $7.3 \pm 2 \mathrm{pA}$ at $\Delta V=-100 \mathrm{mV}$. This measurement was repeated four times at least to obtain a statistical average, which informs the plot of the $I V$ curve (Fig. 6c). The conductance $76 \pm 2 \mathrm{pS}$ of silylated $\gamma$-CDNTs is identical to that of unmodified $\gamma$-CDNTs $(76 \pm 2 \mathrm{pS})$. These measurements confirm that the $\gamma$-CDNT silylation does not modify the internal structural parameters and conformation of the nanotube. We also observe that an increase in the channel lifetime in the membrane silylation could prevent self-aggregation.

To increase the channel conductance, a vinylated group of high hydrophobicity was used (Fig. 6d). The current trace is
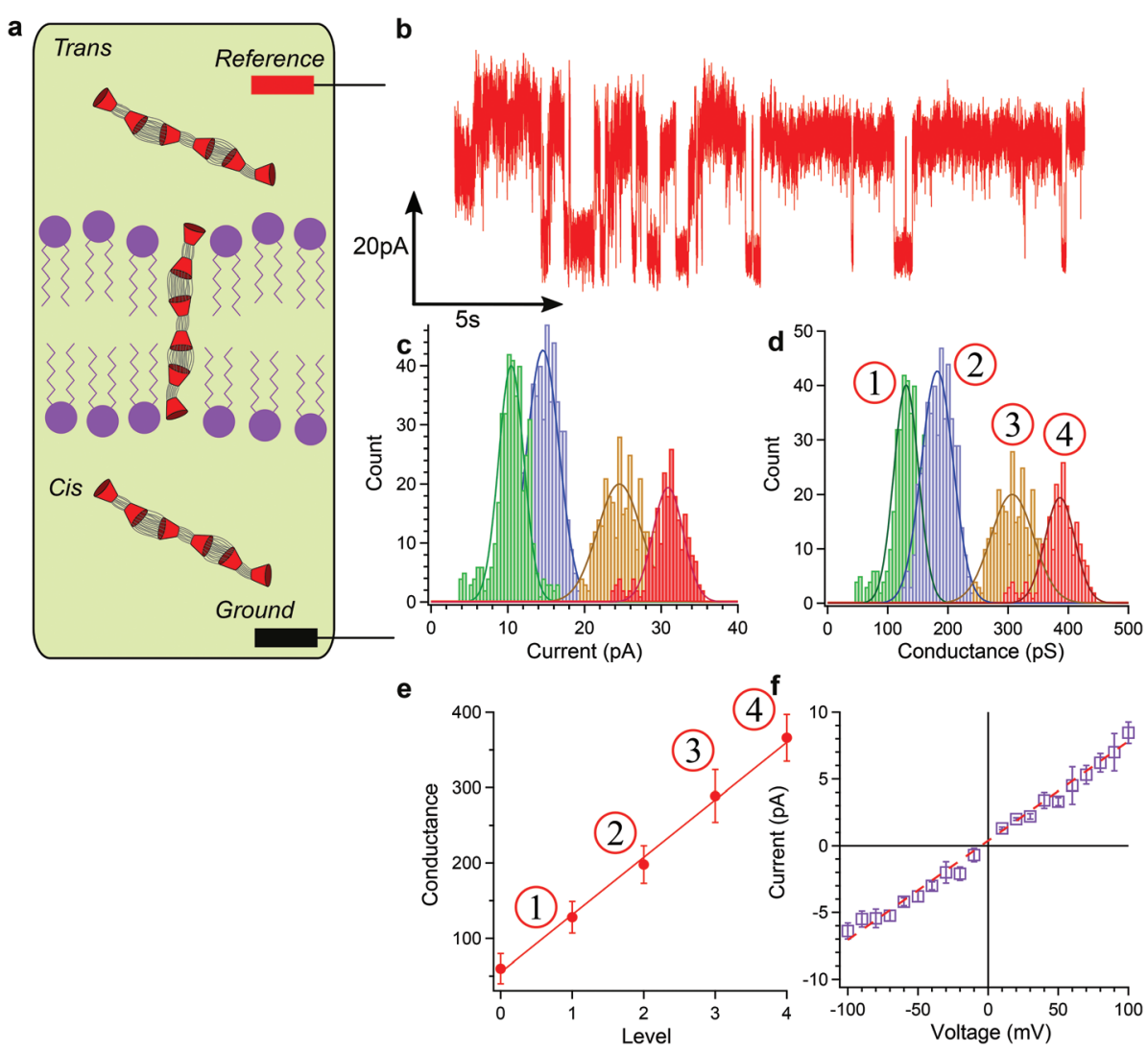

Fig. 5 Electrical characterization of $\gamma$-CDNTs in a lipid membrane: (a) sketch of insertion of CDNTs into a lipid bilayer. Both electrodes apply a potential difference and measure the ionic current between the cis and trans compartments, $1 \mathrm{M} \mathrm{KCl} \mathrm{buffer.} \mathrm{(b)} \mathrm{Part} \mathrm{of} \mathrm{a} \mathrm{current} \mathrm{trace} \mathrm{measured} \mathrm{in}$ the presence of $\gamma$-CDNTs, $1 \mathrm{M} \mathrm{KCl}$ buffer, $\Delta V=80 \mathrm{mV}$. (c) Histogram of current steps obtained from the current trace. Each peak is fitted by a Gaussian function. Each numbered peak corresponds to the insertion of one CDNT. (d) Current of each peak as a function of the number of inserted CDNTs. The unitary conductance of the CDNT is equal to the slope of the straight line: $80 \pm 9 \mathrm{pS}$. (e) Current-voltage curve obtained from current traces. Error bars are processed from the standard deviation of the unitary current. The dashed line represents a linear fit, the slope of which equals the CDNT conductance $76 \pm 2 \mathrm{pS}$. 

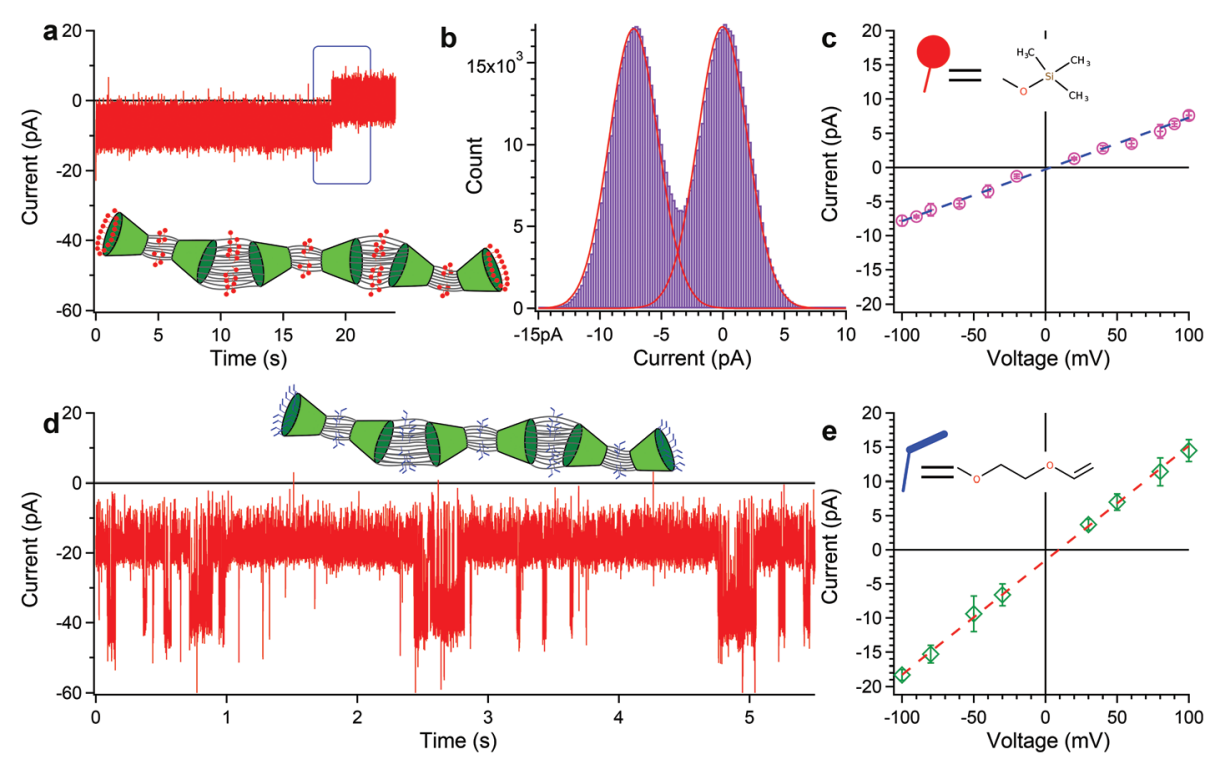

Fig. 6 Chemical modification of CDNTs: (a) current trace measured in the presence of silylated $\gamma$-CDNTs, $1 \mathrm{M} \mathrm{KCl}$. $\Delta V=-100 \mathrm{mV}$, trimethyl silylated groups are substituted with hydroxyl groups of each chain connected to CD groups and are symbolized by green spheres. The blue rectangle shows the region of interest. (b) Histogram of the region of interest of the current trace measured in the presence of silylated $\gamma$-CDNTs. Each peak is fitted by a Gaussian function, showing a current step of $7.3 \pm 2 \mathrm{pA}$. (c) Current-voltage curve measured in the presence of silylated $\gamma$-CDNTs. The dashed line represents a linear fit, the slope of which equals the CDNTs conductance $76 \pm 2 \mathrm{pS}$. (d) Current trace in the presence of vinylated $\gamma$-CDNTs, $1 \mathrm{M}$ $\mathrm{KCl}, \Delta V=-100 \mathrm{mV}$, (e) current-voltage curve measured in the presence of vinylated $\gamma$-CDNTs. The dashed line represents a linear fit, whose slope is equal to the CDNTs conductance $167 \pm 6 \mathrm{pS}$.

consistent through a long recording suggesting sensing capabilities. Moreover, the $I V$ curve shows that the conductance increases by a factor of two from 76 to $167 \pm 6 \mathrm{pA}$. This result is in agreement with the unmodified $\gamma$-CDNT conductance (Fig. 6e).

To compare all the geometrical and chemical modifications of biomimetic nanotubes in terms of their ionic conductance, normalized current-voltage representations were plotted. From a theoretical point of view, ${ }^{99}$ the ionic conductance of a cylindrical single channel reads as:

$$
G=2 \pi r^{2} c \lambda / \ell \exp \left(-\delta E / k_{\mathrm{B}} T\right)
$$

where $r$ is the channel radius, $\ell$ is the channel length, $c$ is the $\mathrm{KCl}$ concentration in water, $\lambda$ is the $\mathrm{KCl}$ conductance in water, $T$ is the absolute temperature, $k_{\mathrm{B}}$ is the Boltzmann constant and $\delta E$ is the energy barrier amplitude for the entry of ions into the confined channel. We were able to increase the NT length from $2.70 \pm 0.70 \mathrm{~nm}$ to $4.40 \pm 0.90 \mathrm{~nm}$ while keeping the nanotube section constant $(0.43 \pm 0.04 \mathrm{~nm}$ and $0.44 \pm$ $0.06 \mathrm{~nm}$ respectively). Then, we processed the ionic current by multiplying it by the channel length $\ell$ to plot the normalized $I V$-curves (Fig. 7a). These curves are linear following an Ohm's law: $I \times \ell=(G \times \ell) \Delta V$ versus the applied voltage $\Delta V$. We can see that both $I V$-curves have the same slope. Therefore, we can deduce that the energy barrier amplitude $\delta E$ of the entry of ions into NT is the same whatever the NT length is. These amplitudes are comparable for short $\delta E_{\text {short }}=2.7 \pm 0.1 k_{\mathrm{B}} T$ and long NTs $\delta E_{\text {long }}=2.9 \pm 0.2 k_{\mathrm{B}} T$. Under our experimental con- ditions, the ion penalty for entry into the NT is independent of the nanotube length. However, we do not observe the same behavior if we modify the NT section.

Next, we wanted to compare $\gamma$-CDNTs' ionic conductance and structural parameters according to the threading process with either two thin PEO chains or one single PIB chain. In the former case, we followed the same procedure described with $\alpha$-CDNTs. ${ }^{79}$ As $\gamma$ CDs are larger than $\alpha \mathrm{CD}$, the two PEO chains induce different rod like structure, in which two EO units of the 2 chains are included inside each $\gamma \mathrm{CD}$ cavity leading to a polyrotaxane containing two PEO chains (Fig. 7b). In the latter, we obtained a polyrotaxane containing one PIB chain (Fig. 7b). This chain behaves like a flexible polymer chain, which prevents the threading from being effective.

Following the same process that was previously performed (Fig. 7a), the ionic current is normalized according to the NT length (Fig. 7b). The linearity of both curves confirms the Ohm's law relevance in both NTs. Nevertheless, both slopes are different: $0.09 \pm 0.02 \mathrm{nS} \mathrm{nm}$ (double thread) and $0.2 \pm 0.02$ $\mathrm{nS} \mathrm{nm}$ (single thread), leading to a ratio of $0.45 \pm 0.15$. Assuming that the energy barrier amplitude $\delta E$ of the ion entry is the same for both nanotubes, abiding by eqn (1) makes this ratio equal to the one for the nanotube section. If we plot the section ratio according to the TEM measurements ( $0.36 \pm$ $0.05 \mathrm{~nm}$ and $0.42 \pm 0.04 \mathrm{~nm}$ respectively), this ratio is equal to $0.7 \pm 0.3$ and is in agreement with the ratio calculated from the ionic current measurements. This ratio is explained by the variation of the threading geometry between double and single threading. In the first case, the cyclodextrin is deformed by 

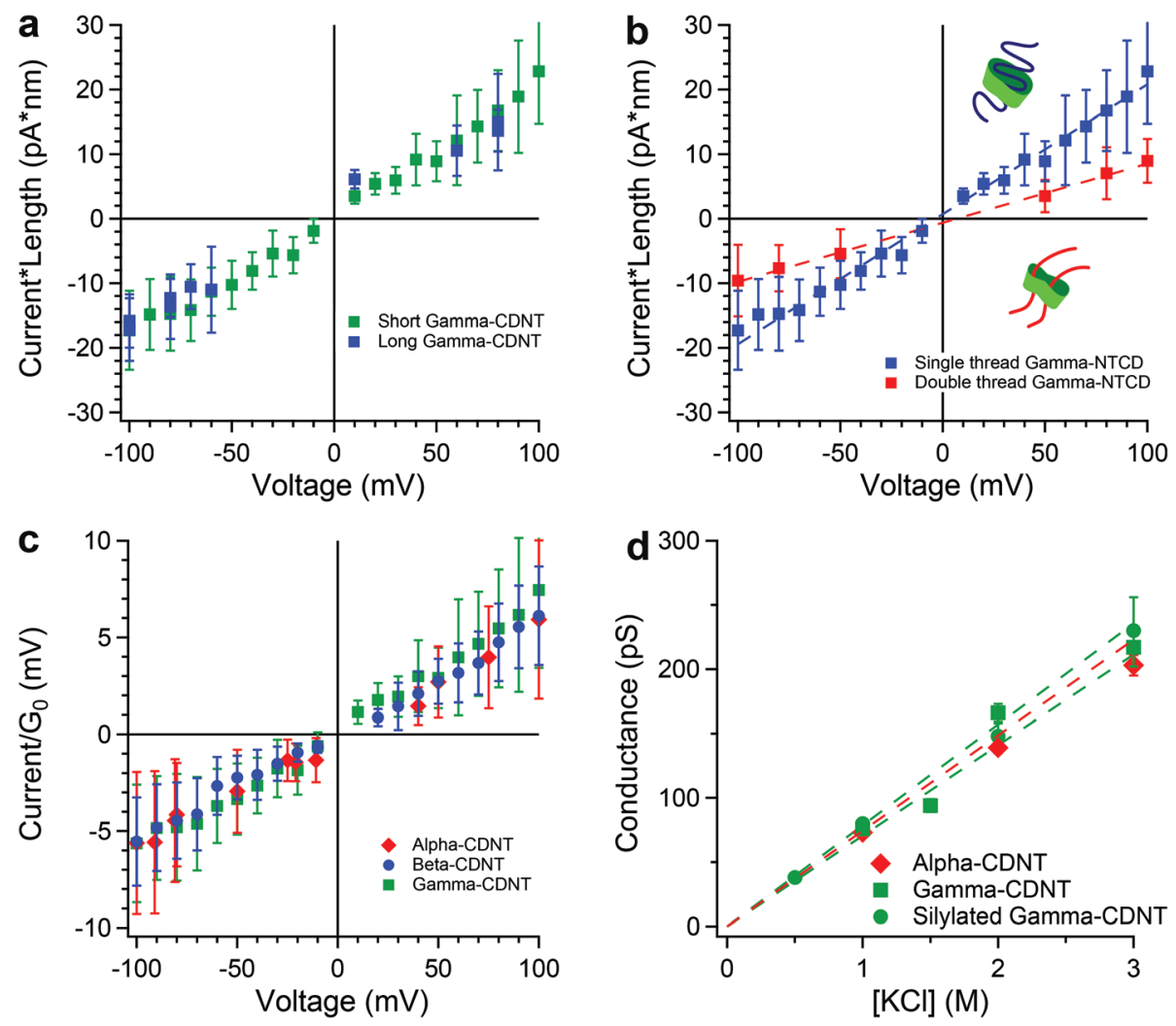

Fig. 7 Normalized current of CDNTs in lipid membranes. (a) Influence of the NT length. lonic current normalized by the NT length versus applied voltage for short $\gamma$-CDNTs (green square) and long $\gamma$-CDNTs (blue squares). (b) Influence of the threading process on the $\gamma$-CDNTs conductance. lonic current normalized by the NT length versus the applied voltage for single thread $\gamma$-CDNTs (blue square) and double thread $\gamma$-CDNTs (red square). (c) Normalized current by its generic conductance $G_{0}$ of $\alpha$ (red diamond), $\beta$ (blue dot), and $\gamma$ (green square) CDNTs. (d) Influence of the ionic force. Conductance versus $\mathrm{KCl}$ concentration for $\alpha$-CDNTs (red diamond), $\gamma$-CDNTs (green square) and silylated $\gamma$-CDNTs (green dot).

both PEO chains and shows a concave shape, while in the second case, the shape tends to be convex with a large apparent diameter (Fig. 7b). These observations show that the CD section is dependent on its environment due to the flexibility of the cyclodextrin ring. These diameters are smaller than that of $\gamma$-CD $(0.95 \mathrm{~nm})$, measured in a $\gamma$-CD crystal. ${ }^{100}$

Another way to check the NT diameter is to plot the reduced current versus the applied voltage for $\alpha$-, $\beta$ - and $\gamma$-CDNTs in the same graph with 6,7 , and 8 glucopyranose units, respectively (Fig. 7c). This reduced current is calculated from the ratio between the ionic current and the conductance $G_{0}=2 \pi r^{2} c \lambda / \ell$ of a cylinder having the same dimensions as the considered NT. By using eqn (1), we process the energy barrier amplitudes $\delta E=3.0 \pm 0.2 k_{\mathrm{B}} T$ for $\alpha$-CDNTs, $2.9 \pm 0.1 k_{\mathrm{B}} T$ for $\beta$-CDNTs and $2.7 \pm 0.1 k_{\mathrm{B}} T$ for $\gamma$-CDNTs. These energy magnitudes are comparable and show that the mechanism of ion entry is independent of the size of each CD unit. Furthermore, we see that the $I V$-curves are linear and are similar to the gramicidin A channel. ${ }^{101}$

Now, we focus on the influence of the salt concentration on the $I V$ curves for $\alpha, \gamma$-CD and silylated NTs. The conductance of the three NTs increases linearly with the $\mathrm{KCl}$ concentration (Fig. 7d). This result confirms that the silylation does not modify the CDNT conductance. The slopes are also compar- able when considering the error bars. This is consistent with HRTEM observations where both NT nanotubes presented similar geometrical properties. Conductive behavior is observed between 0.5 and $3 \mathrm{M} \mathrm{KCl}$ suggesting that the ionic conductance is dominated by the ionic transport inside the nanotube described by Poisson-Nernst-Planck equations..$^{102,103}$

This ionic behavior was previously observed with different biomimetic channels such as those based on a self-assembled cylindrical $\beta$-sheet peptide architecture ${ }^{64,104,105}$ where the internal diameter of the channel $(0.75 \mathrm{~nm})$ is similar to that of the CDNTs. More recently, new channels based on the DNA duplex architecture were synthesized with an internal diameter of $2 \mathrm{~nm}^{68,70-72}$ or $0.8 \mathrm{~nm} .{ }^{106}$ More recently, metal-organic polyhedra, with 0.45 and $0.66 \mathrm{~nm}$ diameters, respectively, were used to control the conductance of a lipid membrane. ${ }^{66}$ An ohmic behavior was observed and the conductance variation as a function of the salt concentration $(\mathrm{KCl})$ saturated at a high salt content. This is explained by the progressive saturation of surface charges of the channel by the counter ions. ${ }^{66}$ In another example, Göpfrich et al. measured a high conductance and observed an ohmic behavior using a larger channel with a DNA architecture vestibule $(20-23 \mathrm{~nm})$ and constriction $(11 \mathrm{~nm}){ }^{73}$ Generally, for channels larger than $2 \mathrm{~nm}$, the con- 
ductance is described by using an ionic model from linear $I-V$ curves measured experimentally or calculated from molecular dynamics. ${ }^{73,107}$ At the same time, other research teams developed a synthesized channel based on the carbon nanotubes (CNTs). In early publications, CNTs were hundreds of nanometers large and long to design nanofluidic devices. ${ }^{108-110}$ This size was reduced to $50 \mathrm{~nm}$ to allow the detection of $\lambda$-DNA based on the variation of the ionic conductance. ${ }^{111}$ This ohmic regime of ion transport is also observed with similar boron nitride nanotubes. ${ }^{112}$

Nevertheless, the sub-2 nm CNT shows an ion rejection, ${ }^{113}$ which is mostly governed by the electrostatic effects among the ionized group at the CNT mouth, the co-ions and the counter-ions. ${ }^{114}$ The same behavior is observed if the CNT is inserted into a lipid bilayer: ${ }^{115,116}$ if the diameter is in the range of 1-2 $\mathrm{nm}$, the pore conductance is described by the usual ionic model. If this diameter is below a critical size, around $1 \mathrm{~nm}$, the $I V$ curve is not linear and the measured conductance is much smaller than the expected one. This behavior could be due to the hydration layer around the ions, which becomes larger than the CNT diameter. The deformation of this shell leads to a strong increase in the energy barrier magnitude of ion insertion into the CNT and could explain the strong decrease of the CNT conductance. Similar behaviors were observed in the case of nanopores drilled into ultra-thin graphene membranes. ${ }^{117}$ In addition, Noy et al. observed that if the conductance of the CNT is larger than this size $(1.51 \pm$ $0.2 \mathrm{~nm}$ large), it is mostly dominated by ionic conductance. ${ }^{75,118}$ Nevertheless, less than $30 \%$ of all the CNTs show transitions between open and partially closed states. This behavior is not due to the ionic conductance. It was first attributed to electro-wetting/dewetting transitions, ${ }^{119}$ but this hypothesis cannot justify the residual current of the partially blocked state. This process seems to be explained by the counterbalance between two opposite mechanisms: ion exclusion, due to the deformation of the hydration shell, and ion penetration, due to the dielectric jump between the bulk and the nanotube for neutral and weakly charged cylindrical nanopores. ${ }^{120}$

Similar transitions between two regimes characterized by ionic and non-ionic conductance are also observed for nanopores drilled in very thin $\mathrm{MoS}_{2}$ membranes. ${ }^{121,122}$ Above a critical size $(1 \mathrm{~nm})$, the conductance is dominated by an ionic process. Below this value, it is governed by ionic Coulomb blockades, characterized by a transition between two energy levels (blocked and open states). As for nanopores drilled in $\mathrm{Si}$ based membranes larger than this critical nanometer size, the conductance is mostly dominated by an ionic effect and shows a linear $I V$-curve. ${ }^{53,123}$

\section{Conclusion}

We have designed and validated, by mass-spectrometry and high-resolution transmission electron microscopy, a general route to synthesize nanotubes from polyrotaxanes based on $\beta$ and $\gamma$-CDs. The synthesis of polyrotaxane based on $\gamma$-CD and
PIB leads to $\gamma$-CD nanotubes with properties comparable to those of $\gamma$-CD nanotubes carried out on either two PEO chains. We have also demonstrated that chemical modifications with silylated or vinylated groups facilitate nanotube insertion, improve their stability in lipid bilayers and avoid multiple channel insertions. Electrical measurements involving these sub-nanometric biomimetic channels show a linear response of the ionic current as a function of the applied voltage and a linear variation of the conductance versus the salt concentration. The normalized $I V$ curves allowed us to highlight the influence of the length, section and nature of CD on the CDNT conductance and to show that the conductance mechanism is mainly due to an ionic transport through these nanotubes. We found that the energy barrier amplitude of the entry of ions into the nanotubes has the same magnitude, around $3 k_{\mathrm{B}} T$, independent of the nanotube length. In the future, we plan to use these nanotubes to study cell cytotoxicity and biomolecule transport in a highly confined biomimetic channel. These nanochips coupled with microfluidic devices would be suitable for biotechnology applications. ${ }^{60,124-127}$

\section{Methods}

\section{Nanotube synthesis general procedure}

Pseudopolyrotaxane formation. The polymer is mixed at room temperature with a saturated solution of cyclodextrin for 24 hours. The inclusion complex precipitates and is gathered by filtration. The crude product is washed several times with an appropriate solvent to eliminate the cyclodextrin and the polymer in excess. The pseudopolyrotaxane is dried under vacuum.

Polyrotaxane formation. The pseudopolyrotaxane, 1-pyrene butyric acid $N$-hydroxysuccinimide ester and sodium persulfate are stirred at room temperature in a mixture of water/DMSO for 1 hour. Once the solvent is evaporated, the crude product is solubilized in a small amount of DMSO and is purified by precipitation in diethyl ether. The purified polyrotaxane is gathered by filtration, solubilized in DMF and dried under vacuum.

Nanotube synthesis. The polyrotaxane is mixed with a $2 \mathrm{M}$ aqueous solution of sodium hydroxide and epichlorohydrin is added dropwise. Then, the mixture is stirred at room temperature for a week. Hydrochloric acid is then added to reach an acidic $\mathrm{pH}$. The mixture is freeze-dried and the crude product is purified by washing with DMSO. The nanotube obtained is purified after drying under vacuum.

$\boldsymbol{\gamma}$-CDNT2300Si synthesis. The silylation reaction of $\gamma$-CDNT2300 was carried out using $\alpha$-cyclodextrins. The nanotube is solubilized in dried dimethylformamide under an inert atmosphere. Trimethylsilylimidazole was added in molar excess. Dried chloroform was used until the reaction mixture became limpid. The reaction is stirred under a static atmosphere at room temperature for one week. The product is dried after quenching with water and washing the organic phase three times. 
$\boldsymbol{\gamma}$-CDNT2300Vi synthesis. $\boldsymbol{\gamma}$-CDNT2300 and NaH are solubilized in dimethylformamide under an inert atmosphere at $0{ }^{\circ} \mathrm{C}$. The mixture is stirred for one hour. 2-Chloroethyl vinyl ether is added dropwise and the mixture is stirred at room temperature for 24 hours. After quenching with ammonium chloride and washing the organic phase three times, the crude product is dried and then purified using Sephadex G25.

\section{Characterization of the CDNTs by MALDI-TOF MS}

MALDI-TOF MS experiments were performed using an Autoflex III MALDI-TOF/TOF spectrometer (Bruker Daltonics Inc., Bremen, Germany). This instrument was equipped with a $\mathrm{Nd}$ : YAG SmartBeam laser $(\lambda=355 \mathrm{~nm})$ pulsed at a $200 \mathrm{~Hz}$ frequency. The mass spectrometer was operated in the negative ion linear/reflector mode with an accelerating potential of $-19 \mathrm{kV}$. Mass spectra were recorded with extraction delay was set to 300 and $800 \mathrm{~ns}$, for reflector and linear mode, respectively. Mass spectra were obtained by accumulation of 1000 laser shots and processed using Mass spectra were automatically processed with Flex Analysis 3.0 software (Bruker Daltonics Inc). The instrument was calibrated using standard peptide and protein mixtures provided by the manufacturer. 1,8-Diaminonaphtalene (1,8-DAN) at $20 \mathrm{mg} \mathrm{mL}^{-1}$ in water/ methanol $1 / 1(\mathrm{v}: \mathrm{v})$ was mixed and used as matrix. Samples for MALDI-MS analysis concentration were prepared by mixing $1 \mu \mathrm{L}$ of NTs sample and an identical volume of matrix. Then, $1 \mu \mathrm{L}$ of the mixture was deposited on a mirror polished stainless steel MALDI target and allowed to dry at room temperature and atmospheric pressure for $20 \mathrm{~min}$. 1,8-Diaminonaphtalene (1,8-DAN) were purchased from Sigma-Aldrich Co. (Saint Quentin Fallavier, France) and ultrapure water was obtained by a Milli-Q apparatus (Millipore, Bedford, MA).

\section{Characterization of the CDNTs by HRTEM}

HRTEM observations were performed using both Jeol2200FS and Titan Themis (FEI) microscopes working at $200 \mathrm{keV}$ and equipped with a GatanUltraScan CCD camera (US1000) or Ceta $(4 \mathrm{k} \times 4 \mathrm{k})$, respectively, and Ultra-High Resolution (UHR) or high resolution pole pieces. The dispersions were made on a pure carbon membrane (Ted Pella, 01840-F 200 mesh grids) without a polymer and were air dried. The Digital Micrograph software was used for the data treatment. The nanotube and cyclodextrin lengths, the diameters and the distances between two NTs were measured manually using the software's "ruler tool". The "Fourier transformation tool" provided information concerning the distance between the cyclodextrins of the same nanotube. As for the number of cyclodextrins borne by a nanotube, it was determined by counting the cyclodextrins one by one.

\section{Electrophysiology setup}

Two compartments (volume $1 \mathrm{~mL}$, Warner Apparatus) are filled by a $1 \mathrm{M} \mathrm{KCl}$ electrolyte solution (Sigma). They are separated by a DphPC lipid bilayer (Avanti Polar Lipids) in $n$-decane (Sigma), painted on a $90 \mu \mathrm{m}$ aperture. ${ }^{3}$ The electrical potential is applied by two $\mathrm{Ag} / \mathrm{AgCl}$ electrodes placed on either sides of the bilayer as shown in Fig. 5a. The ionic current is measured by using a patch-clamp amplifier Dagan 3900A (Dagan) or BLM-120 (Bio-logic) and filtered at $10 \mathrm{kHz}$. Data are acquired using an acquisition card (National Instrument) with a sampling rate of $200 \mathrm{kHz}$. The data treatment is performed by homemade functions based on Igor software (Wavemetrics).

\section{Conflicts of interest}

There are no conflicts to declare.

\section{Acknowledgements}

This research was supported by the "DEFI CNRS Instrumentation aux limites" 2016 \& 2017 and by the ANR-17CE09-0044-02. We thank Benjamin Cressiot and John T. Gonzalez for careful reading and for improving the use of English in the manuscript. We thank Hassen Ramoul for assistance on gamma-CD polyrotaxane synthesis.

\section{References}

1 L. Movileanu, Trends Biotechnol., 2009, 27, 333-341.

2 S. Majd, E. C. Yusko, Y. N. Billeh, M. X. Macrae, J. Yang and M. Mayer, Curr. Opin. Biotechnol, 2010, 21(4), 439476.

3 A. Oukhaled, L. Bacri, M. Pastoriza-Gallego, J. M. Betton and J. Pelta, ACS Chem. Biol., 2012, 7, 1935-1949.

4 E. M. Nestorovich and S. M. Bezrukov, Chem. Rev., 2012, 112, 6388-6430.

5 J. E. Reiner, A. Balijepalli, J. W. F. Robertson, J. Campbell, J. Suehle and J. J. Kasianowicz, Chem. Rev., 2012, 112, 6431-6451.

6 L.-Q. Gu, Science, 2001, 291, 636-640.

7 M. Soskine, A. Biesemans, B. Moeyaert, S. Cheley, H. Bayley and G. Maglia, Nano Lett., 2012, 12, 4895-4900.

8 M. F. Breton, F. Discala, L. Bacri, D. Foster, J. Pelta and A. Oukhaled, J. Phys. Chem. Lett., 2013, 4, 2202-2208.

9 F. Piguet, F. Discala, M.-F. Breton, J. Pelta, L. Bacri and A. Oukhaled, J. Phys. Chem. Lett., 2014, 5(24), 4362-4367.

10 M. Boukhet, F. Piguet, H. Ouldali, M. Pastoriza-Gallego, J. Pelta and A. Oukhaled, Nanoscale, 2016, 18352-18359.

11 A. Asandei, I. Schiopu, M. Chinappi, C. H. Seo, Y. Park and T. Luchian, ACS Appl. Mater. Interfaces, 2016, 8, 13166-13179.

12 G. Huang, K. Willems, M. Soskine, C. Wloka and G. Maglia, Nat. Commun., 2017, 8, 935.

13 Y. Wang, D. Zheng, Q. Tan, M. X. Wang and L.-Q. Gu, Nat. Nanotechnol., 2011, 6, 668-674.

14 X. Zhang, Y. Wang, B. L. Fricke and L.-Q. Gu, ACS Nano, 2014, 8, 3444-3450.

15 J. W. F. Robertson, C. G. Rodrigues, V. M. Stanford, K. A. Rubinson, O. V. Krasilnikov and J. J. Kasianowicz, Proc. Natl. Acad. Sci. U. S. A., 2007, 104, 8207-8211. 
16 W. Vercoutere, S. Winters-Hilt, H. Olsen, D. Deamer, D. Haussler and M. Akeson, Nat. Biotechnol., 2001, 19, 248-252.

17 G. Baaken, I. Halimeh, L. Bacri, J. Pelta, A. Oukhaled and J. C. Behrends, ACS Nano, 2015, 9, 6443-6449.

18 F. Piguet, H. Ouldali, F. Discala, M.-F. Breton, J. C. Behrends, J. Pelta and A. Oukhaled, Sci. Rep., 2016, 6, 38675.

19 C. Cao, Y.-L. Ying, Z.-L. Hu, D.-F. Liao, H. Tian and Y.-T. Long, Nat. Nanotechnol., 2016, 11, 713-718.

20 A. E. Chavis, K. T. Brady, G. A. Hatmaker, C. E. Angevine, N. Kothalawala, A. Dass, J. W. F. Robertson and J. E. Reiner, ACS Sens., 2017, 2, 1319-1328.

21 H. Wang, J. Ettedgui, J. Forstater, J. W. F. Robertson, J. E. Reiner, H. Zhang, S. Chen and J. J. Kasianowicz, ACS Sens., 2018, 3(2), 251-263.

22 T. C. Sutherland, Y. T. Long, R. I. Stefureac, I. Bediako-Amoa, H. B. Kraatz and J. S. Lee, Nano Lett., 2004, 4, 1273-1277.

23 L. Movileanu, J. P. Schmittschmitt, J. Martin Scholtz and H. Bayley, Biophys. J., 2005, 89, 1030-1045.

24 A. J. Wolfe, M. M. Mohammad, S. Cheley, H. Bayley and L. Movileanu, J. Am. Chem. Soc., 2007, 129, 14034-14041.

25 C. P. Goodrich, S. Kirmizialtin, B. M. HuyghuesDespointes, A. Zhu, J. M. Scholtz, D. E. Makarov and L. Movileanu, J. Phys. Chem. B, 2007, 111, 3332-3335.

26 L. Mereuta, M. Roy, A. Asandei, J. K. Lee, Y. Park, I. Andricioaei and T. Luchian, Sci. Rep., 2014, 4, 3885.

27 M. Pastoriza-Gallego, M.-F. Breton, F. Discala, L. Auvray, J.-M. Betton and J. Pelta, ACS Nano, 2014, 8, 11350-11360.

28 Z. Ji, S. Wang, Z. Zhao, Z. Zhou, F. Haque and P. Guo, Small, 2016, 12, 4572-4578.

29 G. Oukhaled, J. Mathé, A.-L. Biance, L. Bacri, J.-M. Betton, D. Lairez, J. Pelta and L. Auvray, Phys. Rev. Lett., 2007, 98, 158101.

30 C. Merstorf, B. Cressiot, M. Pastoriza-Gallego, A. Oukhaled, J. M. Betton, L. Auvray and J. Pelta, ACS Chem. Biol., 2012, 7, 652-658.

31 D. Rodriguez-Larrea and H. Bayley, Nat. Nanotechnol., 2013, 8, 288-295.

32 J. Nivala, D. B. Marks and M. Akeson, Nat. Biotechnol., 2013, 31, 247-250.

33 J. J. Kasianowicz, E. Brandin, D. Branton and D. W. Deamer, Proc. Natl. Acad. Sci. U. S. A., 1996, 93, 13770-13773.

34 Q. Zhao, R. S. S. de Zoysa, D. Wang, D. A. Jayawardhana and X. Guan, J. Am. Chem. Soc., 2009, 131, 6324-6325.

35 F. Olasagasti, K. R. Lieberman, S. Benner, G. M. Cherf, J. M. Dahl, D. W. Deamer and M. Akeson, Nat. Nanotechnol., 2010, 5, 798-806.

36 A. Fennouri, R. Daniel, M. Pastoriza-Gallego, L. Auvray, J. Pelta and L. Bacri, Anal. Chem., 2013, 85, 8488-8492.

37 S. Howorka and Z. Siwy, Chem. Soc. Rev., 2009, 38, 2360-2384.

38 D. H. Stoloff and M. Wanunu, Curr. Opin. Biotechnol., 2013, 24, 699-704.

39 M. Lepoitevin, T. Ma, M. Bechelany, J.-M. Janot and S. Balme, Adv. Colloid Interface Sci., 2017, 250, 195-213.
40 A. Siria, M.-L. Bocquet and L. Bocquet, Nat. Rev. Chem., 2017, 1, 91.

41 C. Dekker, Nat. Nanotechnol., 2007, 2, 209-215.

42 A. Mara, Z. Siwy, C. Trautmann, J. Wan and F. Kamme, Nano Lett., 2004, 4, 497-501.

43 S. Garaj, W. Hubbard, A. Reina, J. Kong, D. Branton and J. A. Golovchenko, Nature, 2010, 467, 190-193.

44 H. Arjmandi-Tash, L. A. Belyaeva and G. F. Schneider, Chem. Soc. Rev., 2016, 45, 476-493.

45 M. Tsutsui, M. Taniguchi, K. Yokota and T. Kawai, Nat. Nanotechnol., 2010, 5, 286-290.

46 S. K. Min, W. Y. Kim, Y. Cho and K. S. Kim, Nat. Nanotechnol., 2011, 6, 162-165.

47 J. Feng, K. Liu, R. D. Bulushev, S. Khlybov, D. Dumcenco, A. Kis and A. Radenovic, Nat. Nanotechnol., 2015, 10, 1070-1076.

48 J. D. Uram, K. Ke, A. J. Hunt and M. Mayer, Small, 2006, 2, 967-972.

49 K. Zhou, L. Li, Z. Tan, A. Zlotnick and S. C. Jacobson, J. Am. Chem. Soc., 2011, 133, 1618-1621.

50 A. McMullen, H. W. de Haan, J. X. Tang and D. Stein, Nat. Commun., 2014, 5, 4171.

51 M. Wanunu, T. Dadosh, V. Ray, J. Jin, L. McReynolds and M. Drndić, Nat. Nanotechnol., 2010, 5, 807-814.

52 D. S. Talaga and J. Li, J. Am. Chem. Soc., 2009, 131, 9287-9297.

53 A. Oukhaled, B. Cressiot, L. Bacri, M. Pastoriza-Gallego, J.-M. Betton, E. Bourhis, R. Jede, J. Gierak, L. Auvray and J. Pelta, ACS Nano, 2011, 5, 3628-3638.

54 K. J. Freedman, S. R. Haq, J. B. Edel, P. Jemth and M. J. Kim, Sci. Rep., 2013, 3, 1638.

55 C. Plesa, S. W. Kowalczyk, R. Zinsmeester, A. Y. Grosberg, Y. Rabin and C. Dekker, Nano Lett., 2013, 13, 658-663.

56 E. C. Yusko, B. R. Bruhn, O. M. Eggenberger, J. Houghtaling, R. C. Rollings, N. C. Walsh, S. Nandivada, M. Pindrus, A. R. Hall, D. Sept, J. Li, D. S. Kalonia and M. Mayer, Nat. Nanotechnol., 2016, 12, 360-367.

57 P. Waduge, R. Hu, P. Bandarkar, H. Yamazaki, B. Cressiot, Q. Zhao, P. C. Whitford and M. Wanunu, ACS Nano, 2017, 11, 5706-5716.

58 N. Varongchayakul, D. Huttner, M. W. Grinstaff and A. Meller, Sci. Rep., 2018, 8, 1017.

59 J. Y. Y. Sze, A. P. Ivanov, A. E. G. Cass and J. B. Edel, Nat. Commun., 2017, 8, 1552.

60 Y. Lin, Y.-L. Ying, X. Shi, S.-C. Liu and Y.-T. Long, Chem. Commun., 2017, 53, 11564-11567.

61 E. C. Yusko, J. M. Johnson, S. Majd, P. Prangkio, R. C. Rollings, J. Li, J. Yang and M. Mayer, Nat. Nanotechnol., 2011, 6, 253-260.

62 S. W. Kowalczyk, L. Kapinos, T. R. Blosser, T. Magalhães, P. van Nies, R. Y. H. Lim and C. Dekker, Nat. Nanotechnol., 2011, 6, 433-438.

63 A. L. Sisson, M. R. Shah, S. Bhosale and S. Matile, Chem. Soc. Rev., 2006, 35, 1269-1286.

64 M. R. Ghadiri, J. R. Granja and L. K. Buehler, Nature, 1994, 369, 301-304. 
65 M. Jung, H. Kim, K. Baek and K. Kim, Angew. Chem., Int. Ed., 2008, 47, 5755-5757.

66 R. Kawano, N. Horike, Y. Hijikata, M. Kondo, A. CarnéSánchez, P. Larpent, S. Ikemura, T. Osaki, K. Kamiya, S. Kitagawa, S. Takeuchi and S. Furukawa, Chem, 2017, 2, 393-403.

67 N. A. W. Bell and U. F. Keyser, FEBS Lett., 2014, 588, 3564-3570.

68 M. Langecker, V. Arnaut, T. G. Martin, J. List, S. Renner, M. Mayer, H. Dietz and F. C. Simmel, Science, 2012, 338, 932-936.

69 S. Hernández-Ainsa, N. A. W. Bell, V. V. Thacker, K. Göpfrich, K. Misiunas, M. E. Fuentes-Perez, F. MorenoHerrero and U. F. Keyser, ACS Nano, 2013, 7, 6024-6030.

70 J. R. Burns, A. Seifert, N. Fertig and S. Howorka, Nat. Nanotechnol., 2016, 11, 152-156.

71 A. Seifert, K. Goepfrich, J. R. Burns, N. Fertig, U. F. Keyser and S. Howorka, ACS Nano, 2015, 9, 1117-1126.

72 J. R. Burns, K. Göpfrich, J. W. Wood, V. V. Thacker, E. Stulz, U. F. Keyser and S. Howorka, Angew. Chem., Int. Ed., 2013, 52, 12069-12072.

73 K. Göpfrich, C.-Y. Li, M. Ricci, S. P. Bhamidimarri, J. Yoo, B. Gyenes, A. Ohmann, M. Winterhalter, A. Aksimentiev and U. F. Keyser, ACS Nano, 2016, 10, 8207-8214.

74 B. Cressiot, S. J. Greive, W. Si, T. C. Pascoa, M. Mojtabavi, M. Chechik, H. T. Jenkins, X. Lu, K. Zhang, A. Aksimentiev, A. A. Antson and M. Wanunu, ACS Nano, 2017, 11(12), 11931-11945.

75 J. Geng, K. Kim, J. Zhang, A. Escalada, R. Tunuguntla, L. R. Comolli, F. I. Allen, A. V. Shnyrova, K. R. Cho, D. Munoz, Y. M. Wang, C. P. Grigoropoulos, C. M. AjoFranklin, V. A. Frolov and A. Noy, Nature, 2014, 514, 612-615.

76 T. Umeyama, J. Baek, Y. Sato, K. Suenaga, F. AbouChahine, N. V. Tkachenko, H. Lemmetyinen and H. Imahori, Nat. Commun., 2015, 6, 7732.

77 J. R. Burns, N. Al-Juffali, S. M. Janes and S. Howorka, Angew. Chem., Int. Ed., 2014, 53, 12466-12470.

78 G. Hong, S. Diao, A. L. Antaris and H. Dai, Chem. Rev., 2015, 115, 10816-10906.

79 H. Mamad-Hemouch, H. Ramoul, M. Abou Taha, L. Bacri, C. Huin, C. Przybylski, A. Oukhaled, B. Thiébot, G. Patriarche, N. Jarroux and J. Pelta, Nano Lett., 2015, 15, 7748-7754.

80 M. J. Pregel, L. Jullien and J.-M. Lehn, Angew. Chem., Int. Ed. Engl., 1992, 31, 1637-1640.

81 N. Madhavan, E. C. Robert and M. S. Gin, Angew. Chem., Int. Ed., 2005, 44, 7584-7587.

82 P. V. Jog and M. S. Gin, Org. Lett., 2008, 10, 3693-3696.

83 T. Saha, A. Roy, M. L. Gening, D. V. Titov, A. G. Gerbst, Y. E. Tsvetkov, N. E. Nifantiev and P. Talukdar, Chem. Commun., 2014, 50, 5514.

84 E. Busi, G. Vitiello, M. Niccoli, R. Basosi, D. Montesarchio and G. D'Errico, Biochim. Biophys. Acta, Biomembr., 2013, 1828, 2074-2082.

85 Y. Astier, O. Braha and H. Bayley, J. Am. Chem. Soc., 2006, 128, 1705-1710.
86 G. Crini, Chem. Rev., 2014, 114, 10940-10975.

87 B. Wang, E. Zaborova, S. Guieu, M. Petrillo, M. Guitet, Y. Blériot, M. Ménand, Y. Zhang and M. Sollogoub, Nat. Commun., 2014, 5, 5354.

88 A. Harada, Y. Takashima and H. Yamaguchi, Chem. Soc. Rev., 2009, 38, 875.

89 E. M. M. Del Valle, Process Biochem., 2004, 39, 1033-1046.

90 M. E. Davis and M. E. Brewster, Nat. Rev. Drug Discovery, 2004, 3, 1023-1035.

91 A. Harada, J. Li and M. Kamachi, Nature, 1993, 364, 516-518.

$92 \mathrm{~J} . \mathrm{Wu}, \mathrm{H}$. He and C. Gao, Macromolecules, 2010, 43, 22522260.

93 M. Okada and A. Harada, Org. Lett., 2004, 6, 361-364.

94 G. Kali, H. Eisenbarth and G. Wenz, Macromol. Rapid Commun., 2016, 37, 67-72.

95 A. Takahashi, R. Katoono and N. Yui, Macromolecules, 2009, 42, 8587-8589.

96 F. Blin, C. Przybylski, V. Bonnet, M.-J. Clément, P. A. Curmi, P. Choppinet, T. Nakajima, H. Chéradame and N. Jarroux, Macromolecules, 2016, 49, 3232-3243.

97 N. Jarroux, P. Guégan, H. Cheradame and L. Auvray, J. Phys. Chem. B, 2005, 109, 23816-23822.

98 C. Przybylski, F. Blin and N. Jarroux, Macromolecules, 2011, 44, 1821-1830.

99 P. C. Jordan, Biophys. Chem., 1981, 13, 203-212.

100 M. R. Sambrook and S. Notman, Chem. Soc. Rev., 2013, 42, 9251.

101 S. B. Hladky and D. A. Haydon, Biochim. Biophys. Acta, Biomembr., 1972, 274, 294-312.

102 J. Cervera, B. Schiedt and P. Ramirez, Eur. Lett., 2005, 71, $35-41$.

103 S. Balme, F. Picaud, M. Manghi, J. Palmeri, M. Bechelany, S. Cabello-Aguilar, A. Abou-Chaaya, P. Miele, E. Balanzat and J. M. Janot, Sci. Rep., 2015, 5, 10135.

104 R. J. Brea, C. Reiriz and J. R. Granja, Chem. Soc. Rev., 2010, 39, 1448-1456.

105 J. Montenegro, M. R. Ghadiri and J. R. Granja, Acc. Chem. Res., 2013, 46, 2955-2965.

106 K. Göpfrich, T. Zettl, A. E. C. Meijering, S. HernándezAinsa, S. Kocabey, T. Liedl and U. F. Keyser, Nano Lett., 2015, 15, 3134-3138.

107 K. Göpfrich, C.-Y. Li, I. Mames, S. P. Bhamidimarri, M. Ricci, J. Yoo, A. Mames, A. Ohmann, M. Winterhalter, E. Stulz, A. Aksimentiev and U. F. Keyser, Nano Lett., 2016, 16, 4665-4669.

108 L. Sun and R. M. Crooks, J. Am. Chem. Soc., 2000, 122, 12340-12345.

109 T. Ito, L. Sun and R. M. Crooks, Anal. Chem., 2003, 75, 2399-2406.

110 T. Ito, L. Sun, M. A. Bevan and R. M. Crooks, Langmuir, 2004, 20, 6940-6945.

111 R. Fan, R. Karnik, M. Yue, D. Li, A. Majumdar and P. Yang, Nano Lett., 2005, 5, 1633-1637.

112 A. Siria, P. Poncharal, A.-L. Biance, R. Fulcrand, X. Blase, S. T. Purcell and L. Bocquet, Nature, 2013, 494, 455-458. 
113 J. K. Holt, Science, 2006, 312, 1034-1037.

114 F. Fornasiero, H. G. Park, J. K. Holt, M. Stadermann, C. P. Grigoropoulos, A. Noy and O. Bakajin, Proc. Natl. Acad. Sci. U. S. A., 2008, 105, 17250-17255.

115 L. Liu, C. Yang, K. Zhao, J. Li and H.-C. Wu, Nat. Commun., 2013, 4, 2989.

116 L. Liu, J. Xie, T. Li and H.-C. Wu, Nat. Protoc., 2015, 10, 1670-1678.

117 T. Jain, B. C. Rasera, R. J. S. Guerrero, M. S. H. Boutilier, S. C. O'Hern, J.-C. Idrobo and R. Karnik, Nat. Nanotechnol., 2015, 10, 1-6.

118 R. H. Tunuguntla, A. Escalada, V. A. Frolov and A. Noy, Nat. Protoc., 2016, 11, 2029-2047.

119 M. R. Powell, L. Cleary, M. Davenport, K. J. Shea and Z. S. Siwy, Nat. Nanotechnol., 2011, 6, 798-802.

120 S. Buyukdagli, M. Manghi and J. Palmeri, J. Chem. Phys., 2011, 134, 74706.
121 J. Feng, K. Liu, M. Graf, D. Dumcenco, A. Kis, M. Di Ventra and A. Radenovic, Nat. Mater., 2016, 15, 850-855.

122 J. Feng, M. Graf, K. Liu, D. Ovchinnikov, D. Dumcenco, M. Heiranian, V. Nandigana, N. R. Aluru, A. Kis and A. Radenovic, Nature, 2016, 536, 197-200.

123 B. Cressiot, A. Oukhaled, G. Patriarche, M. PastorizaGallego, J. M. Betton, L. Auvray, M. Muthukumar, L. Bacri and J. Pelta, ACS Nano, 2012, 6, 6236-6243.

124 E. M. Nelson, V. Kurz, J. Shim, W. Timp and G. Timp, Analyst, 2012, 137, 3020.

125 K. Briggs, H. Kwok and V. Tabard-Cossa, Small, 2014, 10, 2077-2086.

126 R. Tahvildari, E. Beamish, V. Tabard-Cossa and M. Godin, Lab Chip, 2015, 15, 1407-1411.

127 J. Roman, N. Jarroux, G. Patriarche, O. Français, J. Pelta, B. Le Pioufle and L. Bacri, ACS Appl. Mater. Interfaces, 2017, 9(48), 41634-41640. 